\title{
Denton A. Cooley: maestro cirujano y educador
}

\author{
Denton A. Cooley: Master surgeon and educator
}

Jorge Cervantes*

Departamento de Cirugía, Hospital ABC, Ciudad de México, México

El 18 de noviembre de 2016 murió en su casa, en Houston, a la edad de 96 años, el Dr. Denton Arthur Cooley, uno de los más famosos cirujanos del siglo XX (Fig. 1)1.

Cooley nació en Houston, Texas, de familia acomodada que le permitió acceder a una educación superior, primero en la Universidad de Texas en Galvestón y después a graduarse en la Escuela de Medicina de la Universidad Johns Hopkins en Baltimore, donde se interesó desde temprano en la cirugía cardiovascular bajo la dirección del jefe de cirugía Dr. Alfred Blalock, a quien ayudó siendo residente en 1944 en la histórica operación para paliar la grave cianosis de los pacientes con tetralogía de Fallot efectuándoles una derivación de la arteria subclavia a la arteria pulmonar, conocida después como la operación de Blalock-Taussig, que originó fama mundial a dicha universidad y fue sin duda el arranque de la cirugía cardíaca de la era moderna².

Al terminar la residencia de cirugía en Hopkins en 1951, Cooley pasó un año trabajando con el pionero de la cirugía cardíaca en Inglaterra Sir Russel Brock, y al regresar a Houston inició su relación de muchos años con el destacado cirujano Michael DeBakey, formando un gran equipo de cirugía cardiovascular responsable de grandes avances en la cirugía de la aorta y los grandes vasos, la cirugía vascular periférica, la derivación aortocoronaria con la vena safena y una gran variedad de procedimientos para tratar las cardiopatías congénitas, convirtiendo a Houston en uno de los más prestigiados centros de cirugía cardíaca del mundo.
El 3 de diciembre de 1967, Christian Barnard, en Sudáfrica, revolucionó el ámbito de la cirugía al efectuar el primer trasplante cardíaco en humanos, que fue seguido el 3 de mayo de 1968 por el primer trasplante de corazón en el hemisferio occidental por el Dr. Cooley en el St. Lukes Episcopal Hospital en Houston, donde se inició una gran rivalidad con el Dr. DeBakey, culminando con el rompimiento total cuando el Dr. Cooley implantó el primer corazón artificial el 4 abril de 1969 a un paciente con grave falla cardíaca mientras lograba obtener un donador adecuado. El implante funcionó durante 64 horas hasta que se consiguió el donante y Cooley efectuó el trasplante, pero el paciente murió al día siguiente por neumonía. El programa de corazón artificial era dirigido por el Dr. DeBakey, quien se enfureció por el audaz hecho efectuado sin su autorización y acusó a Cooley, quien fue amonestado por el American College of Surgeons y expulsado del Baylor College of Medicine, orillándolo a fundar el Texas Heart Institute en Houston, donde continuó su brillante carrera. A la edad de 50 años ya había efectuado más de 5000 operaciones cardíacas y ahí continuó operando hasta la edad de 87 años, cuando se vio obligado a retirarse de los quirófanos por un serio problema de artritis deformante de las manos. Su producción científica a lo largo de la carrera fue enorme, con más de 1400 artículos publicados y 12 libros; uno de los últimos llevó el título de 100,000 Hearts ${ }^{3}$.

El Doctor Cooley fue un indiscutible líder de la cirugía mundial y recibió numerosos honores. En 1984, el

\section{Correspondencia:}

*Jorge Cervantes

Paseo de la Reforma, 2233 


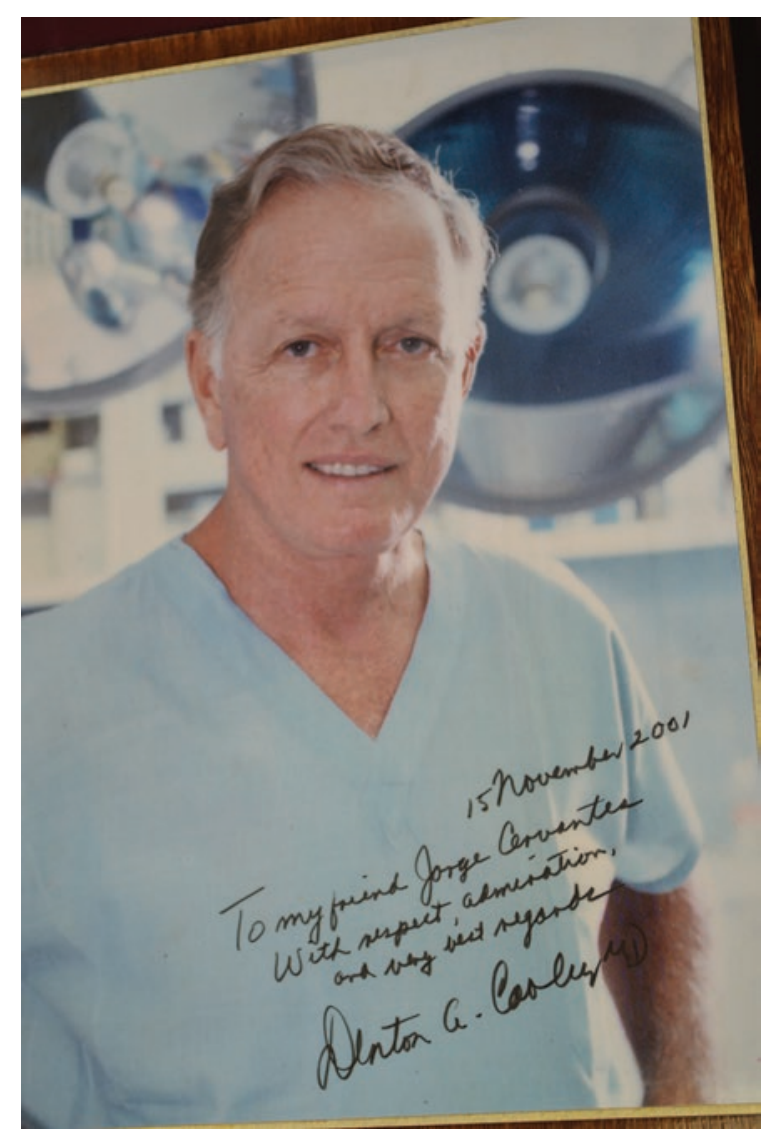

Figura 1. Doctor Denton A. Cooley.

presidente Ronald Reagan le concedió la Presidential Medal of Freedom, que es la distinción más alta que a un civil le hace el gobierno de los Estados Unidos, y la International Surgical Society/Societé Internationale de Chirurgié le concedió la Medalla Rene Leriche, honrándolo como el cirujano cardiovascular más distinguido del mundo. En 1980 se fundó la Denton A. Cooley Surgical Society agrupando a cientos de sus alumnos que brillaban en sus ámbitos locales gracias al entrenamiento recibido bajo su magistral dirección y ejemplo. Muchos cirujanos mexicanos fueron afortunados de tenerlo como maestro y fueron numerosas las ocasiones en que el Dr. Cooley participó en eventos quirúrgicos en nuestro país.

El feudo con el Dr. DeBakey duró más de 40 años, hasta que el 7 de noviembre de 2007, en un evento especial de la Denton Cooley Surgical Society, el Dr. Cooley, que tenía entonces 87 años, le ofreció a su maestro, el Dr. Michel DeBakey, de 99 años, un gran homenaje. DeBakey, en silla de ruedas, recuperándose de una grave cirugía cardíaca, recibió agradecido el reconocimiento y estrechó efusivamente la mano de su distinguido alumno.

El Dr. Cooley estuvo casado durante 67 años con Louise Thomas, su novia que conoció en Baltimore cuando estudiaba medicina. Ella murió antes que él. Tuvieron cinco hijas que les dieron 16 nietos y 17 bisnietos.

Descansa en paz, querido Doctor Denton A. Cooley. Su memoria será recordada con cariño por todos los que tuvimos el privilegio de conocerle.

\section{Conflicto de intereses}

El autor declara que no existe conflicto de intereses.

\section{Bibliografía}

1. Fraser Jr CD. Denton A. Cooley, August 22, 1920, to November 18, 2016. Ann Thorac Surg. 2017;103:1676-8.

2. Cooley DA. The first Blalock-Taussig shunt. J Thorac Cardiovasc Surg. 2010;140:750-1.

3. Weisse AB. 100,000 Hearts: A Surgeon's Memoir. En: Baylor University Medical Center Proceedings. 2012;25(3):297-9. 